\title{
Institucionalização de processo aderente ao CMMI-DEV ML3 em uma empresa exportadora de software
}

\author{
Cesar A. Rodrigues, Álvaro F. Santos ${ }^{1}$, Thiago L. Paiva ${ }^{1,}$ Marcelo W. Barbosa ${ }^{1}$ \\ ${ }^{1}$ Vetta Technologies LTDA. - Alameda da Serra 400 conjunto 701 \\ 34.000-000 - Nova Lima - MG - Brasil \\ \{cesar, alvaro, thiagolp, mwerneck\} @vettatech.com
}

\begin{abstract}
This paper describes the use of effective institutionalizaton mechanisms applied to processes aligned to CMMI-DEV Maturity Level 3 in an organizational unit of Vetta, a software exporting company. The main activities performed to institutionalize the software processes are presented and analyzed according to the company's reality.
\end{abstract}

Resumo. Este artigo apresenta a experiência da aplicação de mecanismos para institucionalização efetiva de processos alinhados ao Nível 3 de Maturidade do CMMI-DEV em toda unidade organizacional da Vetta, empresa exportadora de software. As principais atividades realizadas para institucionalização dos processos de software são apresentadas e avaliadas do ponto de vista da realidade da empresa.

\section{Introdução}

As exportações brasileiras de softwares crescem de forma significativa. Segundo a Associação Brasileira das Empresas de Software (ABES), em 2006, o país exportou US\$ 247 milhões em softwares e serviços, 39,7\% a mais que em 2005. Em 2007, a expectativa era repetir o ritmo de crescimento, de forma que as exportações chegassem ao patamar de US\$ 350 milhões [ABES 2007].

Do volume de exportação de 2006, José Curcelli, presidente da ABES, avalia que menos de $10 \%$ do valor seja proveniente de pequenas e médias empresas. "Exportar demanda estratégia e fôlego financeiro. Não há incentivo. São poucas as pequenas empresas que conseguem", diz o executivo [Zaparolli 2007].

Contrária a essa tendência, a Vetta é uma empresa de médio porte (aproximadamente 75 pessoas) voltada ao mercado externo. Fundada em 2001 com o intuito de atender a uma demanda que existia nos Estados Unidos, a empresa já expandiu seus negócios para outros países: Canadá, Finlândia, Alemanha, França, Suíça e Portugal. Hoje, com sede em Nova Lima, MG, a Vetta possui também escritórios nos Estados Unidos e em São Paulo [Coutinho 2008].

Em reconhecimento à sua atuação como exportadora, a Vetta recebeu o prêmio Destaque de Comércio Exterior, concedido pelo Ministério do Desenvolvimento, Indústria e Comércio em parceria com a Associação de Comércio Exterior do Brasil, em 2004. 
Em 2007, a Vetta conquistou o Nível 3 de Maturidade do CMMI for Development [Chrissis, Konrad e Shrum 2006][Bush, Dunaway 2005]. O CMMI (Capability Maturity Model Integration) é um Modelo para orientar a Melhoria de Processos em Organizações. Definido pelo SEI (Software Engineering Institute) da Universidade de Carnegie Mellon, é um dos modelos mais reconhecidos no mundo. Para atingir o Nível 3 de Maturidade do CMMI, a Vetta atendeu 17 diferentes áreas de processo definidas pelo modelo. Hoje no Brasil pouco mais de 20 empresas possuem ao menos o Nível 3 de Maturidade [SEI 2008].

A escolha do CMMI como modelo de melhoria para os processos da Vetta foi automática devido ao seu caráter exportador e ao reconhecimento internacional do CMMI. Menos óbvia que a escolha do modelo, no entanto, foi a decisão da empresa de não acelerar o processo de avaliação CMMI. Tendo iniciado o processo de melhoria em 2004, a Vetta buscou investir na melhoria dos seus processos de engenharia de software e atingir, como conseqüência natural, o Nível 3 [West 2004].

Um ponto decisivo na escolha da estratégia de melhoria dos processos foi a constatação de que toda a unidade de desenvolvimento e manutenção de software deveria ser avaliada. A Vetta, por ser uma empresa de médio porte, precisa ter toda a sua equipe preparada para trabalhar em projetos de exportação para atender adequadamente ao mercado externo. Desta forma, a institucionalização da melhoria dos processos deveria ocorrer em toda a unidade organizacional, deixando-a 100\% apta para a execução de um processo alinhado ao CMMI-DEV ML3. Caso contrário, a Vetta, já avaliada, teria que atender ao mercado externo com parte de sua equipe ainda não totalmente capacitada nos processos, o que poderia acarretar em problemas de imagem, confiabilidade do mercado externo, dentre outros prejuízos.

O presente artigo relata a experiência da Vetta como empresa exportadora na busca pelo CMMI-DEV ML3 e algumas das atividades de institucionalização aplicáveis a toda unidade organizacional. O restante do relato é organizado da seguinte forma: A seção 2 descreve brevemente os trabalhos de ajuste do processo de software. A seção 3 apresenta as principais iniciativas na busca pela institucionalização por completo. A seção 4 apresenta resultados obtidos do processo e a seção 5 apresenta as considerações finais acerca do processo de melhoria.

\section{Implementação da melhoria de software}

Desde sua fundação, a Vetta já possuía processos de software. Seu processo, denominado VSDP - Vetta Software Development Process, foi criado com base no Rational Unified Process (RUP) [Kruchten 2003] e mantém similaridades quanto à estrutura de fases e disciplinas do RUP.

Em meados de 2004, a Vetta iniciou o alinhamento de seu processo ao CMMISW integrando-se a um grupo de empresas organizadas pela Fumsoft no projeto "Rumo ao CMMI". Para esse projeto, foi contratada a empresa ASR Consultoria, responsável pelos treinamentos, consultorias e avaliações preliminares e simuladas.

O trabalho de consultoria foi desenvolvido normalmente. Ao final de 2004, o VSDP já se encontrava alinhado ao CMMI ML2. No segundo semestre de 2006 foi 
realizada pela consultoria a avaliação simulada final (pré-assessment), que levantou os últimos pontos de ajuste para permitir a aderência definitiva do VSDP ao CMMI ML3.

A partir dos ajustes decorrentes da avaliação simulada final, a Vetta estava apta para realizar sua avaliação CMMI-DEV ML3 com base em projetos-piloto. Entretanto, com foco no atendimento com qualidade ao mercado externo, iniciou-se o programa para capacitar toda a unidade organizacional de Desenvolvimento e Manutenção de Software, que corresponde a $90 \%$ do faturamento da empresa. Esse programa de institucionalização do VSDP perdurou até a avaliação oficial, realizada em 2007.

\section{Programa de institucionalização}

O programa de institucionalização dos processos de software da Vetta consistiu em uma série de atividades voltadas para a capacitação da equipe e da institucionalização dos processos. Durante o programa, algumas atividades de capacitação já existentes na Vetta foram intensificadas, enquanto outras novas foram aplicadas. Dentre todas as medidas adotadas, as seguintes merecem destaque: Projeto Vetterano, investimento em identificação com os processos, Aprendiz Vetta e treinamentos diretos.

\subsection{Projeto Vetterano}

O Projeto Vetterano é um mecanismo criado com o intuito de garantir a transferência de conhecimentos técnicos e de cultura organizacional dos membros mais antigos e experientes da equipe para os mais jovens e inexperientes. Desde sua admissão, cada colaborador da Vetta é apresentado ao seu Vetterano, que é um colaborador mais antigo e com maior grau de senioridade que possui por responsabilidade transferir o conhecimento e orientar o "afilhado" em suas decisões e busca do crescimento organizacional.

Os Vetteranos não são necessariamente os profissionais mais seniores da empresa. Um Vetterano sênior pode, por exemplo, ser responsável por um colaborador pleno, que por sua vez pode ser Vetterano de um colaborador júnior. Essa distribuição hierárquica permite que exista um limite saudável do número de "afilhados" que cada Vetterano consegue orientar - tipicamente entre dois e cinco -, valores que garantem atenção adequada no treinamento e acompanhamento realizado pelo Vetterano. A estrutura hierárquica ainda permite que Vetteranos intermediários possam praticar suas habilidades de comunicação e liderança gradativamente, à medida que ganham experiência profissional.

A lista que contém os Vetteranos de cada membro da equipe da Vetta é formalmente definida no plano de capacitação organizacional. Essa lista é revisada a cada seis meses, quando ocorrem as revisões globais do plano de capacitação. Durante esse período, os objetivos de carreira de cada colaborador são reavaliados e as mudanças dos objetivos de médio e longo prazo de cada pessoa podem acarretar na escolha de um Vetterano mais adequado.

Além de colaborar no atendimento aos requisitos da área de processo OT (Organizational Training) do CMMI-DEV, o Projeto Vetterano foi de extrema importância para a institucionalização, uma vez que ele potencializa exponencialmente a transmissão de conhecimento da equipe mais sênior para a equipe mais júnior. Essa 
transferência de conhecimento ainda torna-se mais valiosa em um ambiente de crescimento da empresa, no qual novos colaboradores precisam estar aptos ao trabalho o mais cedo possível e, nem sempre, é possível ministrar um treinamento formal individual. É importante destacar também que alguns dos Vetteranos mais seniores colaboraram na definição dos processos, o que facilita a transmissão dos conhecimentos do VSDP para toda a equipe.

\subsection{Identificação da equipe com os processos}

O investimento com a identificação da equipe com os processos consiste no esforço da Vetta em apresentar o VSDP como ferramenta natural de trabalho. A percepção do processo como parte do trabalho tem por objetivo torná-lo um hábito, de forma a fazer com que a equipe naturalmente busque o processo para executar os projetos e, sob a percepção da importância do mesmo, não consiga executar suas atividades sem ele apenas de uma forma melhor.

Uma das maiores dificuldades na transformação do uso do processo em um hábito encontra-se na motivação da equipe em acessar o processo e lê-lo. Para isso, foram feitas duas medidas: a criação da identificação do processo com as pessoas e a adoção de ferramenta de descrição de processos.

A identificação do processo com as pessoas foi realizada através da criação de representações gráficas do VSDP, seus papéis e suas disciplinas cuja representação dos executores das atividades era feita de forma estilizada baseada nos colaboradores da própria empresa (Figura 1). Simples na concepção, os diagramas estilizados formataram a identidade visual do VSDP. Os conceitos de processos, papéis e disciplinas foram amplamente assimilados pela equipe. Sentindo-se mais próximos do processo de melhoria, os colaboradores se tornaram mais ativos no conhecimento do processo e na busca das informações relacionadas.

Em paralelo com a criação da identidade visual do processo, foi realizado o investimento em melhores formas para a sua apresentação. Desde o início do alinhamento dos processos ao CMMI, a Vetta percebeu a necessidade de se ter uma ferramenta para escrita estruturada de processos e para a apresentação para a equipe. Essa necessidade advém tanto da complexidade de se escrever processos de software corretos em forma textual, quanto da dificuldade e indisposição da equipe na obtenção de informações a partir dos processos escritos nos documentos de texto. Por isso, em 2005, a Vetta iniciou a criação de uma ferramenta para a definição estruturada de processos, denominada WARP. Algum tempo depois foi lançado o Eclipse Process Framework (EPF) [EPF 2008] - uma ferramenta para registro estruturado de processos de software com base na Plataforma Eclipse [Eclipse 2008]. Após avaliação interna, ficou decidida a utilização do EPF como ferramenta para a descrição do VSDP.

A adoção do EPF como ferramenta de descrição de processos, além de colaborar no atendimento aos requisitos da área de processo OPD (Organizational Process Definition), facilitou o acesso da equipe ao processo. Ao invés de estar descrito em documentos textuais, o VSDP tornou-se disponível para acesso remoto, via internet. Além disso, sua apresentação possuía um grau de navegabilidade apropriado para o rápido aprendizado e uso simplificado. Essas vantagens tornavam-se ainda mais significativas para os colaboradores que faziam trabalhos de exportação de software e 
que eventualmente poderiam estar em outros países. Em caso de mudanças no VSDP, elas eram refletidas diretamente no site e seriam automaticamente disponibilizadas para pessoas em qualquer parte do mundo com acesso a um navegador Web.

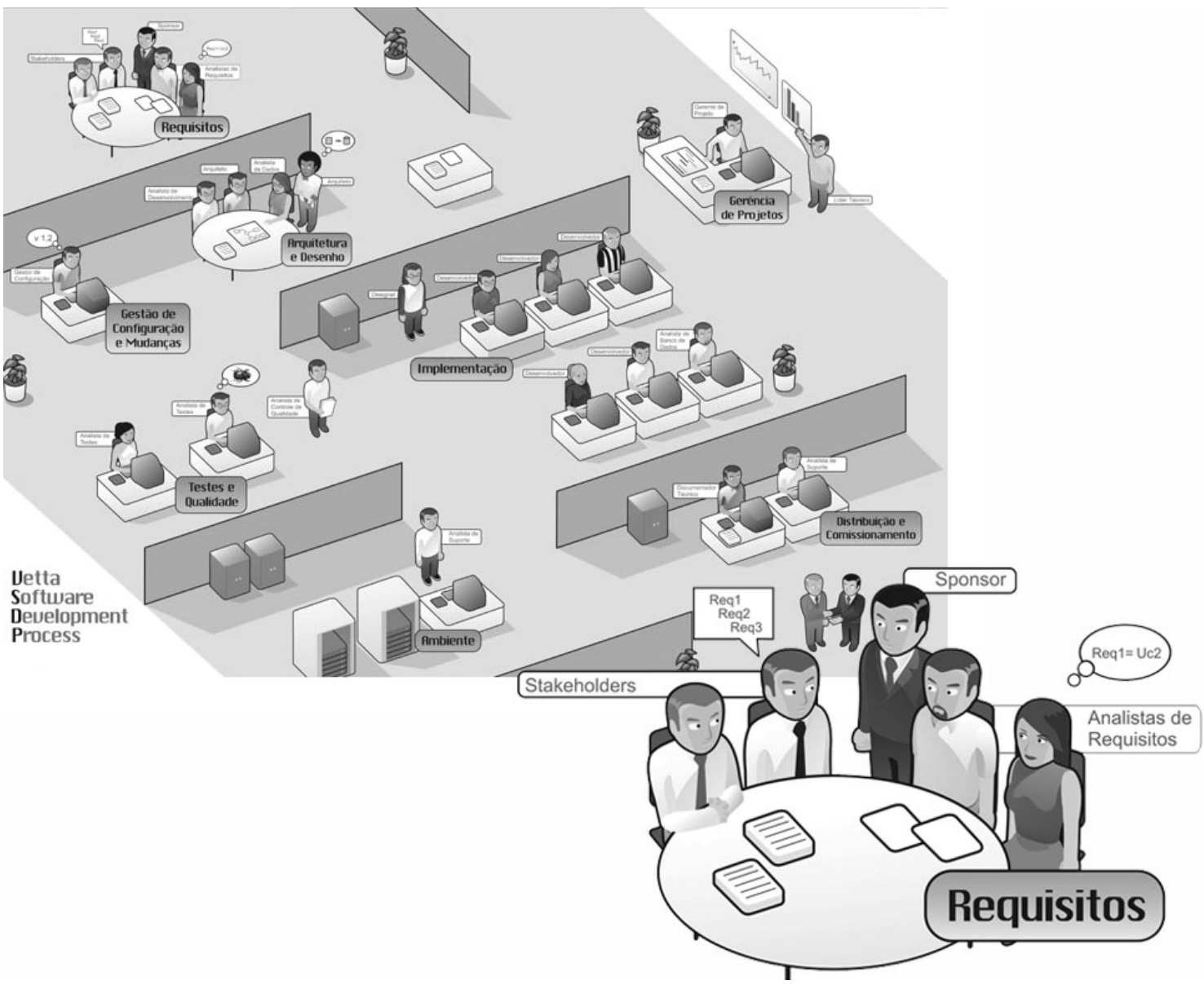

Figura 1. Fluxo geral de atividades e exemplo de detalhes do VSDP, com identificação aos membros da equipe.

\subsection{O Aprendiz}

O Aprendiz Vetta (Figura 2) foi um treinamento estruturado, no formato de competição, que envolveu toda a equipe da unidade organizacional para reforçar o contato com o processo. O objetivo do treinamento era permitir que todos os membros da unidade organizacional pudessem vivenciar a execução de um projeto completo aderente ao VSDP e ressaltar a importância de cada papel.

A unidade organizacional foi dividida em grupos. Cada grupo continha pessoas de diferentes papéis, de forma que os grupos ficariam equilibrados do ponto de vista de experiência e conhecimento técnico. Foi definido um problema, que seria a base para os trabalhos dos grupos. Uma versão simplificada do VSDP, alinhada aos principais conceitos, artefatos e papéis do VSDP completo, foi utilizada.

O treinamento foi organizado em quatro módulos: um para cada fase do ciclo de vida do VSDP (Concepção, Elaboração, Construção e Transição), tendo sido executado em um total de quatro semanas. A cada módulo, os membros das equipes precisariam 
alterar seus papéis no VSDP, de forma que nenhum integrante do grupo repetisse o mesmo papel durante todo o treinamento. Cada grupo deveria resolver o problema seguindo o processo em todo o seu ciclo de vida. Ao final de cada módulo o grupo era avaliado, recebendo pontos por critérios envolvendo a aderência ao processo, o tempo, a qualidade do resultado, dentre outros critérios.

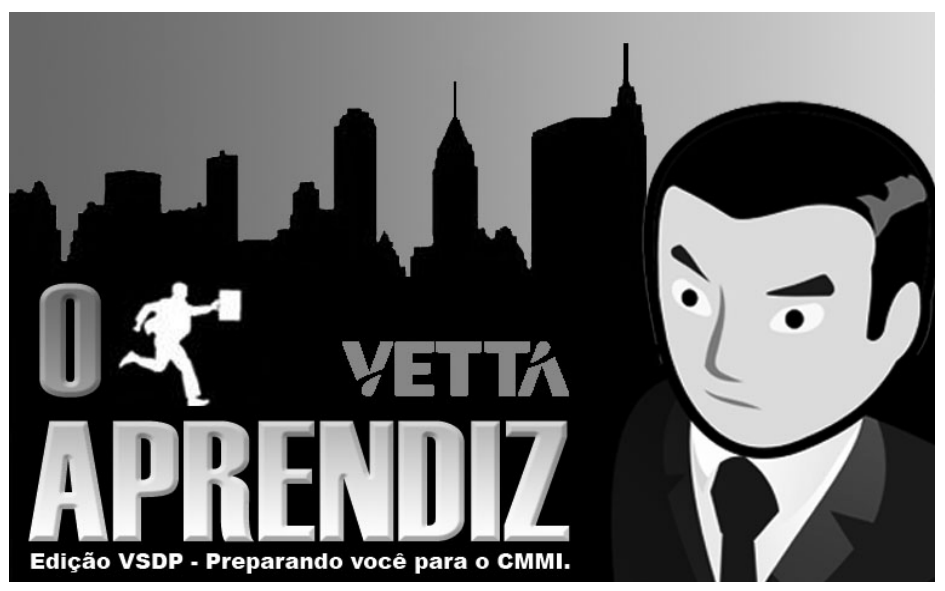

Figura 2. Divulgação interna do programa de treinamentos Aprendiz, com manutenção da identidade visual do processo.

O formato do treinamento apresentou ótimos resultados quanto à ampliação do conhecimento acerca das atividades, papéis, artefatos e comunicações realizadas dentro do VSDP. A leve competição motivou as equipes a lerem proativamente o processo e zelar pela qualidade e o tempo gasto. Esse aprendizado foi percebido mais tarde, durante a execução dos projetos reais. Ao final da competição, a melhor equipe foi premiada, embora tanto as equipes quanto a Vetta tenham ganhado com o treinamento.

\subsection{Treinamentos diretos}

Os treinamentos diretos, por fim, são aqueles realizados diretamente através da preparação de material e divulgação a toda unidade organizacional. Os treinamentos eram realizados após revisões significativas do VSDP como, por exemplo, a versão $100 \%$ aderente ao CMMI-DEV ML3. Cada treinamento era constituído de três principais etapas: treinamento expositivo, estudo dirigido e entrevista.

O treinamento expositivo é a primeira etapa do treinamento direto. Nessa etapa, são ministrados cursos referentes às disciplinas, atividades e técnicas do VSDP, realizados pela equipe interna por instrutores selecionados - que podem ser os Vetteranos com mais experiência e didática. $\mathrm{O}$ objetivo dessa primeira etapa consiste em capacitar a equipe na busca por mais informações sobre o tópico treinado. $\mathrm{O}$ treinamento expositivo não é eficiente sozinho. Como a equipe treinada recebe as informações passivamente, a retenção do conteúdo ministrado nesse treinamento isoladamente não é suficiente.

Após o treinamento expositivo, a equipe treinada recebia um estudo dirigido individual. O estudo dirigido consiste de uma série de questões, exercícios e trabalhos que fazem com que os treinados sejam forçados a investigar o material do processo na busca pelas respostas. $\mathrm{O}$ estudo dirigido serve de complemento para o treinamento 
expositivo, uma vez que possibilita a fixação dos conceitos através do esforço na busca por respostas. Após período adequado, o estudo dirigido é corrigido e discutido, de forma que as dúvidas referentes à execução do exercício possam ser sanadas.

A terceira e última etapa do treinamento é uma entrevista. Realizada por grupos de executores do mesmo papel, a entrevista é realizada pela equipe que elaborou os treinamentos e serve para atestar a efetividade de todo o ciclo de treinamentos ou recomendar um novo estudo dirigido para a pessoa.

O resultado do treinamento direto em três etapas foi extremante significativo, uma vez que não foi recomendada nenhuma reaplicação de estudo dirigido. Todas as atividades de treinamento direto auxiliam no atendimento aos requisitos da área de processo OT (Organizational Training) do CMMI-DEV.

\section{Resultados Obtidos}

O investimento em treinamento, a capacitação dos colaboradores, o tempo para a execução e ganho de maturidade dos processos permitiram que toda unidade organizacional estivesse preparada para a execução proficiente do VSDP no momento da avaliação CMMI-DEV ML3. Após quase um ano de investimentos, a unidade organizacional estava pronta para ser avaliada e assumir as consequiências dessa avaliação, materializada através de projetos solicitados por clientes exigentes do mercado externo.

O processo de institucionalização bem sucedido tem o resultado da avaliação do CMMI ML3 como sua conseqüência direta. Durante o processo de avaliação, tanto os projetos avaliados quanto as entrevistas da equipe foram bem sucedidos. Não foi identificado nenhum ponto fraco, o que acarretou no resultado satisfatório no alcance do CMMI-DEV ML3.

\section{Considerações finais}

O mercado de exportação possui uma dinâmica diferente dos mercados locais. Em primeiro lugar, existe maior exigência pelas referências de qualidade. Enquanto no Brasil uma empresa CMMI-DEV ML3 apresenta diferencial de qualidade, em alguns mercados de outros países (como nos Estados Unidos), o CMMI-DEV ML3 vem se tornando o patamar mínimo de referência de qualidade aceitável. Apenas os níveis mais altos (ML4 e ML5) são considerados diferenciais. Dentro desse contexto, para uma empresa CMMI-DEV ML3 poder atuar nos mercados externos mais competitivos, é necessário que a implementação do CMMI seja eficiente, de forma a demonstrar a aplicação de facto, com resultados de produtividade adequados. 
Uma empresa de porte médio, como a Vetta, não pode restringir à utilização das metodologias da qualidade a um pequeno subconjunto de sua equipe. Para competir no mercado externo, é necessário que toda a unidade organizacional execute os processos de forma eficiente e precisa, uma vez que o atendimento inadequado de um cliente pode acarretar no fechamento de portas a todo um segmento de mercado, conseqüência da visibilidade em grupo reduzido de empresas exportadoras de software brasileiras. A institucionalização eficiente dos processos de software necessita de esforços significativos na capacitação da equipe e disseminação da importância da execução dos processos.

Os programas realizados pela Vetta para a institucionalização dos processos buscaram enfoque em diferentes aspectos de capacitação: atividades com foco específico (Aprendiz Vetta e identificação gráfica com o VSDP) x atividades de aplicação geral (treinamentos, provas, entrevistas e programa Vetterano); aprendizado por transferência (treinamentos, provas) x aprendizado por prática de execução das atividades (mentoring, o Aprendiz Vetta, estudos dirigidos); formalismo (treinamentos, provas) $\mathrm{x}$ atividades lúdicas (o Aprendiz Vetta). Essa multiplicidade de meios, formatos e técnicas de transferência de conhecimento foi apontada por membros da equipe da Vetta durante a avaliação CMMI-DEV ML3 como fundamental no aprendizado do processo e no grau de institucionalização obtido.

A experiência advinda de todo o processo de institucionalização foi importante para preparar a empresa para o crescimento com qualidade. Mesmo após a avaliação CMMI ML3, a experiência de institucionalização permite que a empresa possa continuar a crescer mantendo os padrões de qualidade: a estimativa é que a empresa dobre de tamanho até o final de 2009 e ainda mantenha o mesmo padrão de qualidade.

Sob os aspectos apresentados anteriormente, a institucionalização eficiente e eficaz do processo torna-se fator crítico para a manutenção da Vetta como empresa de destaque na exportação de software.

\section{Referências}

ABES (2007). "Mercado Brasileiro de Software. Panorama e Tendências 2007". Associação Brasileira das Empresas de Software. http://www.abes.org.br/UserFiles/Image/PDFs/Mercado_BR2007.pdf. Acessado em 10/03/2008.

Bush, M.; Dunaway, D. (2005). "CMMI(R) Assessments: Motivating Positive Change". SEI Series in Software Engineering. Addison Wesley Professional.

Coutinho, C. (2008). "Vetta foca no Mercado Externo". Diário do Comércio, Belo Horizonte, 31/01/2008, Negócios, p 15.

Chrissis, M. B.; Konrad, M.; Shrum, S. (2006) "CMMI (Second Edition): Guidelines for Process Integration and Product Improvement". SEI Series in Software Engineering. Addison Wesley Professional.

Eclipse (2008), Eclipse - an open development platform. Disponível em http://www.eclipse.org/. Acessado em 10/03/2008. 
EPF (2008), Eclipse Process Framework Composer. Disponível em http://www.eclipse.org/epf/. Acessado em 10/03/2008.

Kruchten, P. (2003). “The Rational Unified Process: An Introduction”. Addison Wesley.

SEI (2008). "Published Appraisal Results". Software Engineering Institute, Carnegie Mellon. Disponível em http://sas.sei.cmu.edu/pars/. Acessado em 11/05/2008.

West, M. (2004). "Real Process Improvement Using The CMMI". Auerbach, $1^{\text {st }}$ Edition.

Zaparolli, D. (2007). "Corrida de Obstáculos". Valor Econômico, São Paulo, 27/08/2007, Micro e Pequenas Empresas, p. F1. Disponível em http://www2.senado.gov.br/bdsf/bitstream/id/83163/1/noticia.htm acessado em $10 / 03 / 2008$. 